\title{
Dentes Supranumerários: Um Achado Radiológico
}

\author{
Supernumerary Teeth: A Radiographic Finding
}

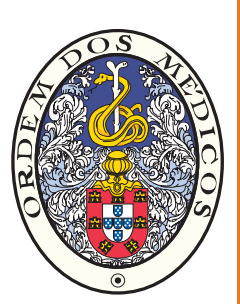

Maria GODINHO ${ }^{1}$, André FIGUEIREDO ${ }^{1}$, André CORREIA ${ }^{1,2}$

Acta Med Port 2014 Mar-Apr;27(2):275-275

Palavras-chave: Dentes Supranumerários; Tomografia Computorizada de Feixe Cónico.

Keywords: Cone-Beam Computed Tomography; Tooth, Supernumerary.

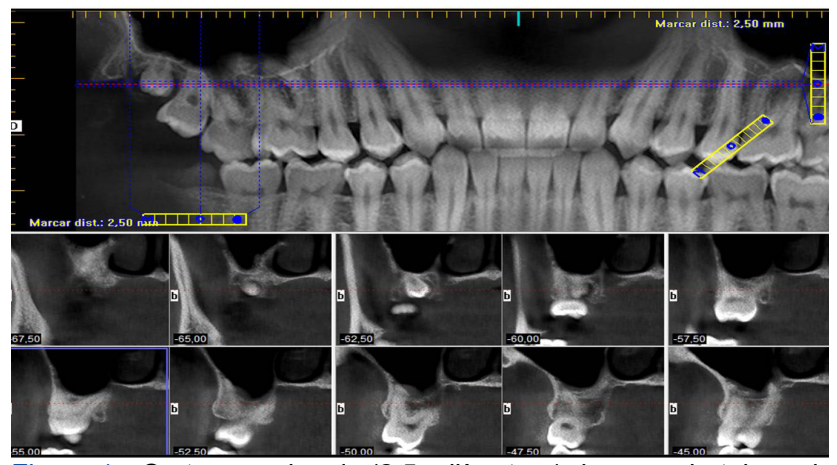

Figura 1 - Cortes seccionais (2,5 milímetros) da zona da tuberosidade maxilar do primeiro quadrante para observação detalhada do dente 18 e distomolar

Homem, 22 anos, saudável dirigiu-se ao Médico Dentista para realizar uma consulta de rotina. $\mathrm{Na}$ análise da ortopantomografia verificou-se a presença de distomolares maxilares, bilaterais e inclusos.

Paciente foi indicado para realizar uma tomografia computorizada de feixe cónico como exame complementar de diagnóstico (Fig.s 1 e 2), para localização e identificação de estruturas dentárias, e possíveis complicações. ${ }^{1,2}$ Este exame permite obter o máximo de informação possível da área envolvida, com o mínimo de radiação. ${ }^{1-3}$

A hiperdontia caracteriza-se por um aumento do número

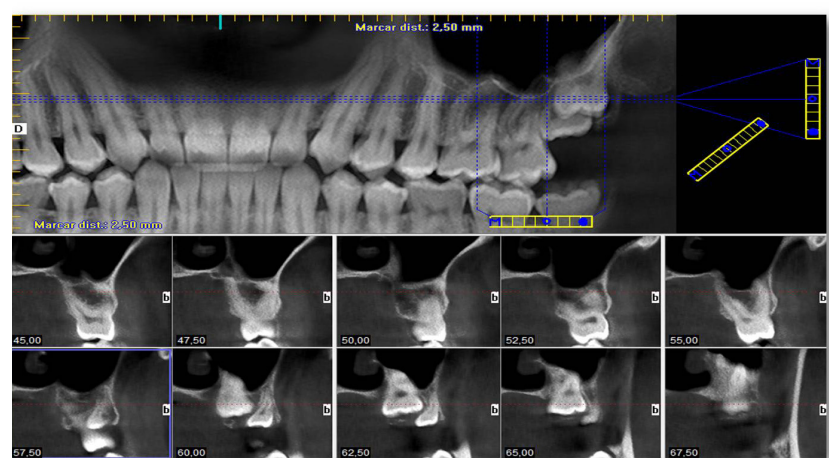

Figura 2 - Cortes seccionais (2,5 milímetros) da zona da tuberosidade maxilar do segundo quadrante para observação detalhada do dente 28 e distomolar

de dentes. ${ }^{4}$ Quando se localiza a distal do terceiro molar, designa-se distomolar, ${ }^{3}$ e apresenta uma prevalência de $2 \% .^{5}$ Apesar da hereditariedade ser um fator etiológico importante, ${ }^{4}$ neste caso, não foi encontrada nenhuma relação.

Devido à ausência de patologia e sintomatologia associada à forte probabilidade de ressecção óssea aquando da intervenção cirúrgica, optou-se pela manutenção de um esquema de consultas de controlo, ${ }^{5}$ com avaliação clínica anual e radiográfica de 3-5 anos.

\section{AGRADECIMENTOS}

Os autores agradecem a Miguel Gonçalves, Director Clínico da Clínica Visage, Viseu, pela disponibilidade na realização da tomografia computadorizada de feixe cónico (CBCT - Cone beam computed tomography).

\section{REFERÊNCIAS}

1. Katheria BC, Kau CH, Tate R, Chen JW, English J, Bouquot J. Effectiveness of impacted and supernumerary tooth diagnosis from traditional radiography versus cone beam computed tomography. Pediatr Dent. 2010;32:304-9.

2. Gurgel CV, Costa AL, Kobayashi TY, Rios D, Silva SM, Machado MA, et al. Cone beam computed tomography for diagnosis and treatment planning of supernumerary teeth. Gen Dent. 2012;60:e131-5.

3. Jacobs R. Dental cone beam CT and its justified use in oral health care. JBR-BTR. 2011;94:254-65.

4. Farahani RM, Zonuz AT. Triad of bilateral duplicated permanent teeth, persistent open apex, and tooth malformation: a case report. J Contemp Dent Pract. 2007;8:94-100.

5. Shahzad KM, Roth LE. Prevalence and management of fourth molars: A retrospective study and literature review. J Oral Maxillofac Surg. 2012;70:272-5.

1. Departamento de Medicina Dentária. Universidade Católica Portuguesa. Viseu. Portugal.

2. Departamento de Ciências da Reabilitação Oral. Universidade Católica Portuguesa. Viseu. Portugal.

Recebido: 18 de Novembro de 2013 - Aceite: 30 de Dezembro de 2013 | Copyright @ Ordem dos Médicos 2014 


\section{Dentes Supranumerários: Um Achado Radiológico \\ Acta Med Port 2014:27:275-275}

Publicado pela Acta Médica Portuguesa, a Revista Científica da Ordem dos Médicos

Av. Almirante Gago Coutinho, 151

1749-084 Lisboa, Portugal.

Tel: +351218428 215

E-mail: submissao@actamedicaportuguesa.com

www.actamedicaportuguesa.com

ISSN:0870-399X | e-ISSN: 1646-0758

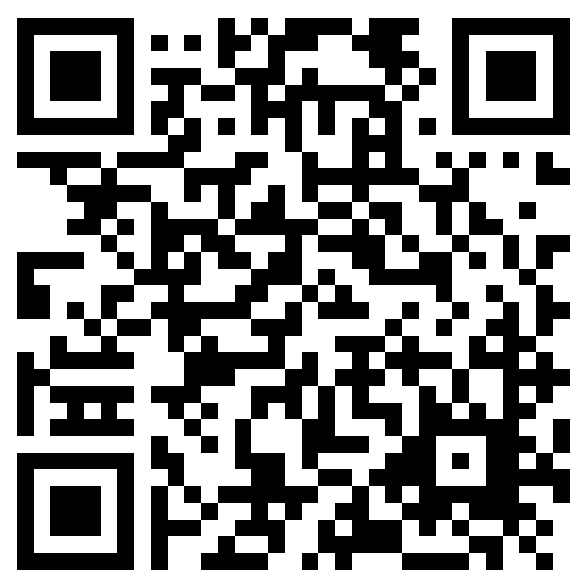

